\title{
EDUCAÇÃO POPULAR DE BASE COMUNITÁRIA E PEDAGOGIA DO COMUM: MEMÓRIA, TRAJETÓRIA E DESAFIOS*
}

\author{
COMMUNITY BASED POPULAR EDUCATION AND PEDAGOGY \\ OF THE COMMON: MEMORY, PATHS AND CHALLENGES
}

Jorge Osorio Vargas ${ }^{\star *}$

\begin{abstract}
RESUMO: O artigo é parte de um projeto do autor que, ao lado de educadores e educadoras da América Latina e do Caribe, pretende recuperar a memória da educação popular e seus critérios de análise acerca da trajetória como educadores e educadoras dos núcleos problemáticos do itinerário histórico-pedagógico dos organizadores de educação popular de base comunitária. A partir dessa perspectiva textual-biográfica são retomados, conforme os critérios do autor, os novos signos que ressignificam a educação popular em uma pedagogia do comum.
\end{abstract}

Palavras-chave: Educação popular; Educação comunitária; Pedagogias; Biograficidade.

ABSTRACT: This article is part of the author's project that together with educators from Latin America and the Caribbean intend to recover their memory about popular educacion and their analysis criteria about their trajectory as educators, and the problematic knots of the historical-pedagogical itinerary of community-based popular education organizations. According to the author's criteria, from this biographical perspective the new signs re-signify popular education as a pedagogy of the common.

Keywords: Popular education; Communitarian education; Pedagogies; Biograficity.

Neste artigo, pretendo compartilhar meu itinerário de trabalho em educação a partir dos anos 2000 , tendo em vista a configuração de um marco de reflexão crítica acerca da trajetória da educação popular. Para tanto, considero importante tecer previamente algumas considerações a respeito do

A primeira versão deste artigo foi publicada em: Jorge Osorio (ed.), Freire entre nos: a 50 años de Pedagogía del oprimido, La Serena: Nueva Mirada Ediciones, 2018. Em função da relevância do tema, foi solicitado que o autor realizasse uma revisão do escrito para ser publicado na revista Trenzar. A presente tradução é baseada na versão da revista Trenzar.

** Docente da Escola de Psicologia da Universidade de Valparaíso (Chile) e diretor do Observatório da Educação de Jovens e Adultos (EPJA) da Universidade de Playa Ancha (Chile). Doutor em direitos humanos e desenvolvimento pelo International Institute of Social Studies (ISS) da Universidade Erasmo de Roterdã (Países Baixos). 
que significa escrever a partir da subjetividade como chave bio-narrativa. Minha primeira intenção é ressaltar o caráter comunitário de minha experiência como educador-pesquisador "em ação", como parte de uma rede humana, intelectual e política de alcance global que tem sido protagonista no desenvolvimento da educação popular, da pesquisa-ação participativa e da educação de adultos em nosso continente. Isso significa que tudo que pude aprender e ensinar, em diversos contextos culturais e institucionais, é fruto do trabalho, dos projetos, das ideias e da audácia intelectual e epistemológica de diversos coletivos e pessoas com quem vivi a experiência de ser parte de uma "comunidade de aprendizagem".

Essa condição basal de minha escrita permite que o presente projeto textual-biográfico seja alimentado pelo passado e pelo presente de outras pessoas, dos cenários de vida cultural e espiritual, bem como das situações de emergência, seja em virtude da criatividade intelectual e pedagógica ou da vivência de situações-limite ocasionadas pela repressão, violência e violação dos direitos humanos. ${ }^{1}$ Não se trata meramente de compartilhar as contingências, mas do desenvolvimento de uma comunhão de significados, reconhecimento, hospitalidade e responsabilidade, processos nos quais adquirem relevância as dimensões próprias do diálogo intercultural, intergeracional e de gênero. A abordagem também vale para interpretar e comunicar os marcos culturais explícitos e tácitos dessa escrita de si, tal como uma auto-etnografia acerca do meu próprio processo formativo nos anos de transição do novo século. ${ }^{2}$ No desenvolvimento deste processo é importante situar este projeto no marco do chamado "giro narrativo" das ciências sociais e seu impacto na pesquisa em educação - proposta que anunciamos como tarefa para os próximos textos. ${ }^{3}$

Assumo esse propósito na medida em que ele parece significativo, seja como projeto acadêmico ou como projeto auto-reflexivo em chave psicoespiritual, tendo em vista o desenvolvimento de minhas capacidades de

\footnotetext{
1 Sobre o bio-texto como outro, ver Mélich (1996).

2 Sobre a criação da narrativa do eu, ver Brunner (2003).

3 Um texto básico e de referência para esse propósito será, conforme nossa própria leitura, Bolívar (2002).
} 
entendimento e de comunicação da complexidade da realidade vivida e das condições subjetivas do meu entendimento das mesmas, não exatamente para elaborar categorias teóricas gerais, mas para sistematizar saberes que permitam a formação de novos projetos pedagógicos a partir do "coração da educação", desde seus arquétipos primordiais sobre as docências e sua ressonância na necessária re-comunitarização da vida humana. ${ }^{4}$

Não menos importante é o desafio desenha e validar uma espécie de auto-metodologia própria para avançar nessa direção. ${ }^{5}$ Nesse sentido, faz muito sentido o enfoque na "aprendizagem a partir das histórias", indicando o desenvolvimento da capacidade de reconhecer saberes contextualizados sociohistoricamente a partir da própria biograficidade. Essa biograficidade atua como:

- Um "pano de fundo" de tais saberes;

- Com campo de aprendizagem, como fonte de processos comunicativos;

- Recuperação da memória pessoal e histórica diante dos conflitos e dissensos;

- Celebração e ritualização da boa vida. ${ }^{6}$

Como complemento ao enfoque sobre a biograficidade e um dos referenciais da escola francesa de pesquisa-ação, René Barbier conceitua a "pesquisa-ação existencial (PAE)".7 Barbier entende a PAE como uma aproximação transversal junto à realidade, vinculando-a aos domínios da intuição, criação e improvisação, relação com o desconhecido, sensibilidade e empatia e capacidade de escuta. Ela é concebida como uma arte heurística e uma poética da experiência e da integridade da vida emocional, sensorial, imaginativa e racional em busca de "rastros" e "sentidos" na dialética de práticas

\footnotetext{
4 Sobre o "coração da educação" e suas manifestações em temas atuais do debate públicopedagógico, ver Osorio (2013).

5 Sobre a tarefa de construção de uma própria auto-metodologia capaz de refletir sobre a experiência do sujeito, sua biograficidade e o desenvolvimento de seus contextos culturais, reconhece a presença e a inspiração do artigo de Xavier Montague (2016). Será preciso explorar como, nessa auto-metodologia, é pertinente e possível incorporar práticas de escrita compartilhadas que permitam tornar visível o caráter comunitário das práticas pedagógicas. Sobre as possibilidades dessa rota de pesquisa em educação, ver G. Schöngut e J. Pujol (2016). ${ }^{6}$ Ver Bettina Dausien (2015).

7 Não encontrei rastros significativos desse enfoque na pesquisa-ação participativa latinoamericana.
} 
e discursos, experiências e narrativas, inclusive como elementos abertos ao transpessoal e às emergências espirituais (BARBIER, 2008). Quatro domínios organizam esse propósito:

- A comunicação de aprendizagens a partir de minhas próprias experiências de vida;

- Itinerários e contextualização bio-histórica no marco convergente das iniciativas e da produção teórica e pedagógica da comunidade de práticas (plural e não ausente de dissensos) da educação popular e comunitária na América Latina;

- Exploração de bases e manifestações pedagógicas de uma educação ecoreflexiva que seja formada a partir do ato primeiro do cuidado, do reconhecimento e da reciprocidade;

- A invocação cidadã permanente da comunitarização da sociedade como via de confronto diante das incertezas e dos riscos da sociedade neoliberal globalizada e disciplinada de modo midiático e líquido, definida por alguns como "sociedade do conhecimento" e por outros como "sociedade da exclusão e do descarte", tendo em vista as perspectivas de um projeto de habitabilidade cidadã que, a partir de sentidos comuns elaborados con-vivencialmente (segundo a noção de Ivan Illich), prime pelo cuidado dos humanos, de suas comunidades e do planeta;

- Formação identitária, valorativa, pedagógica, profissional e cidadã (ecoreflexiva, próximo-complexa) do educador em contexto de diversos processos culturais, epistêmicos, políticos, ambientais e midiáticos e tecnológicos de alta intensidade que desterritorializam as escolas e as ações educacionais convencionais, provocando buscas por novas maneiras e espaços de ensinar e aprender. ${ }^{8}$

\section{RECUPERAÇÃO DA MEMÓRIA}

Em um artigo publicado em 2004, que deve ser lido como um projeto reflexivo e textual de sistematização dos trabalhos de pesquisa-ação e de educação popular, cidadã e de adultos nos quais atuei desde os anos 1970 (OSORIO, 2015), propus que a fase "contemporânea" da educação comunitária latino-americana teve início naquela década marcada pelas propostas de Ivan Illich, pela pedagogia da libertação de Paulo Freire e pela pesquisa-ação participativa promovida por Orlando Fals Borda. Essas tendências logo

\footnotetext{
8 Uma cartografia dessas novas formas de ensinar e aprender pode ser encontrada em Carbonell (2015) e Calvo (2017).
} 
convergiram nos processos de educação popular de base comunitária desenvolvidos, nas décadas seguintes e sob condições políticas diversas (governos reformistas, processos revolucionários, ditaduras militares, resistência social e defesa dos direitos humanos), junto a organizações nãogovernamentais, igrejas, centros de estudo e movimentos e organizações sociais em diversa modalidades, especialmente como "educação política", educação camponesa e rural e formação de dirigentes de base, educação para a organização social das mulheres, alfabetização e educação de adultos e educação em direitos humanos.

No mesmo texto, eu argumentava que, desde o início dos anos 1990, em função da exigência de repensar as bases antropológicas e valorativas da reconstrução das instituições democráticas pós-ditaduras militares e acordos de paz, vislumbramos um novo ciclo da educação popular comunitária, retomando as ideias fundamentais da primeira utopia freireana: a educação emancipadora como possibilidade de desenvolver a comunicação democrática a partir de uma pedagogia do conflito e do diálogo cultural orientada para a construção de um poder popular-cidadão com capacidade auto-constituinte. Assim escrevi:

Este ciclo é um sedimento vivo das autocríticas dos momentos anteriores: estamos diante de um "desmonte", uma desconstrução das "sínteses definitivas", das narrativas fechadas, dos projetos sem alteridade crítica e dos enfoques unilaterais de mudança. A comunidabilidade, como metáfora freireana, nos abre para um mundo plural e híbrido de sujeitos e nos convida à construção de alianças entre movimentos diversos, articulados por uma visão crítica da realidade, além de convidar à constituição de redes de atores sociais dispostos a pensar em um "outro" distinto do pensamento neoliberal. Seguindo essa formulação, podemos assinalar que a educação popular de inspiração freireana é formada com a potencialização da criação de mapas de possibilidades e de atuação para os sujeitos, bem como cursos de ação para que eles - a partir de espaços locais e particulares - sejam capazes de construir alteridades valorativas e novas formas de fazer a política global (OSORIO, 2004). 
Alguns estudos feitos no fim dos anos 1980 na Nicarágua sandinista e no Chile, a partir da prática de defesa dos direitos humanos e de reconstituição de um tecido social democrático, e pesquisas no Peru e no Brasil, tendo em vista as contribuições da educação popular para o campesinato e nos movimentos sociais altermuldialistas, colocaram em relevo o tema da consistência das práticas pedagógicas da educação popular. Esses estudos sustentavam que as ideias educacionais de Paulo Freire haviam sido absorvidas por uma prática política que minimizou os alcances pedagógicos de todo o processo de aprendizagem política. Assim, falava-se de déficit pedagógico da educação popular, banalização das técnicas de grupo utilizadas habitualmente nos programas desenvolvidos junto aos setores populares e de uma perda da capacidade de sistematização e de investigação dos educadores e das educadoras populares (OSORIO, 2003).

No fundo, essa perspectiva crítica sustentava que a educação popular era um método de organização popular que não considerava as dinâmicas pedagógicas, ou seja, as regras e a teoria que relacionavam a política com os processos de geração de aprendizagens e conhecimentos e formas de validação desses saberes. Dizia-se que a educação popular padecia de um pragmatismo, que não conduzia efetivamente a processos de aprendizagem e mudança, tampouco à construção de estratégias de gestão da cultura das comunidades e das formas de organização territorial da educação dos setores populares para além da implementação de ações por meio da tecnologia dos "projetos".

Minha opinião era que não se tratava de uma crise de eficiência, tampouco de uma crise de capacidades pedagógicas, mas de uma realocação do campo próprio da educação popular e de sua contribuição para a criação de maiores poderes aos movimentos sociais mediante novas condições políticas e econômicas demarcadas pela globalização neoliberal no continente. Em sentido estrito, o princípio de identificação central da educação popular, a construção de uma sociedade socialista, era submetido a uma disputa entre as diversas expressões culturais e políticas dos movimentos sociais e da esquerda latinoamericana mesmo antes de 1989. Os movimentos pelos direitos humanos no cone sul, o sandinismo, os movimentos de reconstrução democrática e paz na 
Colômbia, os movimentos sociais brasileiros, o movimento feminista, os primeiros grupos de ecologia política, entre outras manifestações, colocavam as regras do debate político de uma maneira distinta da que havia conhecido a educação popular desde seu processo originário nos anos 1960 e 1970. A meu ver, a ideia subjacente à necessidade de fortalecimento da dimensão pedagógica da educação era a necessidade de construção de um novo conceito prático de poder e de seu correlato no campo da cultura e das aprendizagens para o exercício de um poder social transformador.

A crescente autonomia dos movimentos sociais em relação aos partidos políticos da esquerda histórica, o fortalecimento de novos movimentos cidadãos e políticos (como o Partido dos Trabalhadores, o PT, no Brasil), a emergência de novos sujeitos sociais que trabalhavam na perspectiva de democratização da sociedade em todas as suas dimensões (por exemplo, o movimento feminista), a valorização dos espaços local e regional como âmbitos de refundação de alternativas políticas e a emergência política dos movimentos indígenas (o zapatismo no México) convergiam para a configuração de uma nova "pedagogia política".

Nos ciclos originários da educação popular a teoria da dependência, a teologia da libertação, o humanismo marxista de Paulo Freire e a teoria da educação dialética exerceram muita influência. Dependendo dos contextos nacionais, diversas versões do marxismo desempenharam um papel particular na educação popular (houve "educações populares" maoístas, foquistas, nacional-populares, frentistas e social-democratas), sempre sob o pano de fundo da teoria do conhecimento libertador elaborada por Paulo Freire e seu método dialético de "aprender a ler a realidade para transformá-la". Esse foi o foco comum que tornou a educação popular uma prática educacional crítica e antisistema, pois vinculada aos movimentos de libertação e de resistência, abastecendo os movimentos populares com um sentido de autonomia, entendida como a capacidade cultural de construção de alternativas de esquerda a partir da lógica da ação coletiva e comunitária não necessariamente ditada pelos partidos políticos tradicionais da esquerda. Essa "teoria" da educação popular sofreu resistência por parte de algumas referências políticas revolucionárias que 
entendiam que qualquer processo de mudança social exigia uma vanguarda expressa em um partido ou movimento, aos quais deveriam estar subordinados os sujeitos sociais organizados como movimentos ou comunidades de base. Isso gerou tensões entre a educação popular e suas novas maneiras de entendimento da política e alguns partidos marxistas. Contudo, a teoria autonomista incorporada pela educação popular definiu avant la lettre as expressões populares de base como novos movimentos sociais, já que promoviam a criação de uma nova cultura política fundada na democracia participativa e na criação de um poder popular territorializado e institucionalizado através de formas democráticas.

Nesse período não há indícios de que o marxismo ortodoxo, de cunho soviético, tenha desempenhado algum papel catalizador no imaginário político da educação popular: a própria teoria da educação dialética era mais ligada à "teologia da libertação" e a uma análise sustentada nos manuais de "estudo de conjuntura para educadores populares" criados nos diversos contextos nacionais sob a lógica do "ver, julgar a atuar". Tratava-se de uma metodologia própria dos movimentos cristãos de esquerda que enfatizavam as dimensões culturais que Freire designava à aprendizagem social e políticas das comunidades através dos "círculos de cultura", a "pesquisa temática" e a pesquisa participativa orientada para a ação coletiva. A teoria freireana foi paulatinamente enriquecida por novos enfoques ou "teorias de base" a partir das experiências históricas da educação popular em diversos países: por exemplo, os enfoques em direitos humanos, feminismo, economia popular e desenvolvimento local, eco-política e educação indígena.

Outro fator-chave para o entendimento desse processo crítico era a adoção dos enfoques analíticos de Antonio Gramsci sobre as novas dinâmicas constituintes da educação popular. Com efeito, a influência de Gramsci nos anos 1990 ocasionou uma mudança substantiva na educação popular e comunitária da pedagogia política dos movimentos sociais emergentes, de modo convergente com as contribuições da corrente da pedagogia crítico-dialética (FERRADA; FLECHA, 2008; GHISO, 2000) e as estratégias pedagógicas deliberativas dos movimentos sociais que adquiriam grande visibilidade global 
na conjuntura de 2011 (PADIERNA, 2009; ZIBECHI, 2008; ORTIZ, 2013; TORRES, 2016). Concluí que o "encontro" com Gramsci, por várias razões, é muito positivo para a educação popular e para a reavaliação do trabalho cultural e educacional a partir dos processos identitários e constituintes dos coletivos sociais. Gramsci posiciona o valor estratégico o trabalho "na cultura" para a construção de uma nova hegemonia. A partir deste ponto de vista, ele analisa as instituições culturais burguesas, a Igreja e a educação escolar. Ele valoriza a cultura popular, a linguagem popular e seus saberes e considera fundamental trabalhar a partir de tais cenários, manifestações vernáculas ${ }^{9}$ e imaginários sociais para a construção de um novo conhecimento e de novas práticas políticas (GRAMSCI, 2004).

A partir desse ponto de vista, propus pensar a educação comunitária junto às novas experiências da educação popular e do trabalho comunitário surgidos no Chile durante o processo de transição governamental para a democracia desde 1990, em que eram:

- Redefinidos os argumentos políticos sustentados durante a ditadura (por exemplo, a partir da crítica do patriarcado, da não-sustentabilidade ecológica do neoliberalismo e da economia extrativista e crise da democracia representativa identificada como uma cidadania de "baixa intensidade"), que bloqueavam o exercício de uma democracia participativa ("cidadania insurgente");

- Posicionados, com protagonismo no cenário político, novos sujeitos pedagógicos provenientes de ações emergentes, como os movimentos estudantis, os coletivos de educação libertária e as novas gerações de educadores e educadoras populares que, especificamente no caso chileno, reposicionam os enfoques de trabalho educacional junto aos setores populares em uma perspectiva de democratização radical da sociedade (FAURÉ, 2011; COLLECTIVO DIATRIBA, 2012; GONZÁLEZ; RAMOS, 2013) a partir de organizações feministas, eco-políticas e as redes que promovem "educações alternativas" e "pedagogias e escolas críticas" (OSORIO, 2015).

Essas manifestações resumiam em duas afirmações o que ficava entendido por meio do sentido pedagógico-comunitário das experiências, práticas, projetos e saberes que se manifestavam no contexto emergente pós1990: o debate pedagógico não é precisamente uma questão disciplinar, mas

\footnotetext{
9 Ivan Illich (2016) argumenta que o termo vernáculo implica a ideia de enraizamento, de morada, do que é cultivado em casa em oposição ao que se obtém por trocas.
} 
ética, pois implica o estabelecimento de bases abertas para projetos educacionais amplos e integradores das diversas dimensões do ser humano. Por isso, a condição crucial do debate pedagógico é construir a comunicabilidade, a participação, o diálogo e a educação com uma "esfera pública". A educação comunitária deve ser desenvolvida como uma pedagogia conversacional por meio do confronto de dilemas e encruzilhadas, polêmicas e conflitos gerados na vida cotidiana material e subjetiva, bem como do desenvolvimento dos territórios, bairros e comunidades, além das demandas cidadãs por justiça social e participação democrática. Assim, a educação chega a ser inspiradora de uma ação ampla, reflexiva, situada, significativa, interpretativa, crítica e orientada para a atuação dos sujeitos como "sujeitos coletivo-comunitários".

Levando em consideração essas novas configurações, propus uma agenda pedagógica da educação comunitária de modo que ela transitasse pelas seguintes coordenadas:

- Como processo de produção de identidades em relação a sistemas de poder, redes sociais e intercâmbio de saberes;

- Construindo uma visão política que componha uma plataforma de revitalização da vida pública democrática;

- Nutrindo-se de saberes sociais e culturais que deem sentido às circunstâncias dos sujeitos e de suas comunidades;

- Estabelecendo-se como uma "pedagogia da diversidade" por meio da qual o trabalho educacional sobre os direitos e identidades culturais de gênero, étnicas, etárias e de localidade exige uma crítica da historicidade negativa do neoliberalismo e do desmonte das estruturas culturais e institucionais de toda discriminação, exclusão, estigmatização, humilhação e vulnerabilidade da dignidade humana (OSORIO, 2004).

Eu associava a educação comunitária ao desafio de construir cidadanias democráticas ativas e insurgentes através de: ampliação dos direitos civis e sociais de homens e mulheres; a prática de ações democráticas diretas; uma intervenção mais contundente nas agendas de opinião pública, por meio do controle cidadão das políticas governamentais; uma reinvenção das instituições de poder local, como espaços de reconstrução das relações sociais, culturais e econômicas da sociedade civil popular; criação de capacidades e competências 
para controlar (accountability) a autoridade política a partir de organizações e movimentos cidadãos de base comunitária e territorial como um processo associativo protagonizado por redes e opinião pública local e regional, entendendo a política como construção do poder, dos direitos e de responsabilidades (empowerment).

Em 2006, participando de um livro coletivo sobre os novos contextos, atores e desafios da educação popular latino-americana (OSORIO, 2006), voltei a dedicar atenção ao significado de uma pedagogia comunitária. Dessa vez, como uma proposta de "pedagogia do comum", valorizando as experiências dos movimentos sociais locais e globais altermundialistas, ecologistas, feministas, de direitos humanos, da juventude, indígenas e de reivindicação de memórias históricas colono-invisibilizadas. Esse enfoque pensava os processos como espaços de educação, de afecção mútua, reciprocidade, cuidado, solidariedade e construção de "sentidos de comunidade" (PAREDES, 2013) que chegaram a ter expressão mundial na conjuntura de 2011 em movimentos como os Indignados, os protestos de cidadãos, o M-15 espanhol e o movimento estudantil no Chile (HALL, 2012; CASTELLS, 2012; ORTIZ; BURKE; BERRADA; SAENZ, 2013; TORRES, 2015; FAURÉ; MIRANDA, 2016).

\section{ENFOQUES PEDAGÓGICOS NEO-PARADIGMÁTICOS QUE REDIMEN- SIONAM A EDUCAÇÃO POPULAR DE BASE COMUNITÁRIA EMERGENTE: PARA UMA PEDAGOGIA DO COMUM}

Em 2007, Alejandro Cussiánovich, educador peruano, assessor de organizações para crianças que reivindicam direitos e referência da educação popular latino-americana desde os anos 1970, publicou um ensaio que sistematiza uma proposta educacional chamada "pedagogia da ternura". Ele a define com uma resposta à condição humana desvalorizada das crianças e jovens nos países de nossa região, estimulado pelo protagonismo dos movimentos das crianças e das mulheres organizadas pela defesa de direitos como sujeitos protagonistas da mudança educacional (CUSSIÁNOVICH, 2010). O notável nessa proposta é que ela está situada em uma situação de busca e de reconhecimento da incerteza que caracteriza os processos de mudança social 
em contexto neoliberal global, confiando nas ferramentas, na disposição e na capacidade reflexiva da educação popular de base comunitária e, por extensão, dos movimentos sociais.

Apenas um ponto de vista de complexidade e do olhar ecológico permitem discernir as condições de exclusão social dominantes e as vias de construção de sociedades justas. A "ternura" é a forma de mobilizar o desenvolvimento da capacidade de acolhimento, reconhecimento, vinculação e cuidado na sociedade, conduzindo-os a uma dimensão política por meio do protagonismo (voz, organização, transformação) dos sujeitos mobilizados junto à experiência de "relacionar-se com os outros a partir de uma posição de buscas de sentidos comuns de vida e de aprendizagem da agência social" com conteúdos ecológicos, não-patriarcais e não-autoritários.

A educação política das comunidades, então, é fundamentalmente uma educação do vínculo radical do acolhimento e da expansão da vivência do comunitário ao nível individual e local para a construção de relações sociais fundadas nos direitos humanos, na justiça social e na não-discriminação. ${ }^{10}$ Mediante marcos convergentes, foi desenvolvido um enfoque pedagógico chamado "do cuidado, da hospitalidade e da alteridade". Conforme o filósofo colombiano Santiago Vallejo:

A pedagogia da alteridade se converte em um modelo que permite reencantar a realidade, narrá-la e experimentá-la de diversas maneiras. É uma perspectiva que abre as portas para um contexto não-totalitário, a uma existência construtora de sentidos e significações que permitam a cumplicidade do aluno e do professor, não a impossibilidade nem o estranhamento (VALLEJO, 2014).

Conclui, assim, o mesmo Vallejo (2014):

\footnotetext{
${ }^{10} \mathrm{Em} 2013$ tive contato, em castelhano, com o livro do filósofo e teólogo brasileiro Hugo Assmann (2013). Ele desenvolve os fundamentos epistêmicos e pedagógicos de uma sociedade de aprendizagem a partir das chamadas ciências da vida inspiradas nas contribuições de Francisco Varela e Humberto Maturana, pedagogicamente situada, de modo lúcido e cultural, junto a Francisco Gutiérrez (2015) na Costa Rica, também com grande impacto na formação das novas gerações de educadores comunitários, pesquisadores socio-educacionais e docentes em vários países de nossa região.
} 
Para uma pedagogia da alteridade também é importante fazer referência a dois conceitos de vital importância: a hospitalidade e a experiência. Nesse sentido, a hospitalidade constitui o momento no qual se realiza o instante do acolhimento, quando se reconhece ao indivíduo o que ele é, um ser humano que carrega intrinsecamente o desejo de aprendizado e, por sua vez, carrega consigo uma história e uma memória que permitem avivar a rememoração. Graças à memória existem os outros, aqueles que passaram mas que nunca foram esquecidos, já que eles também fazem parte de nós, da interminável construção identitária feita cotidianamente. Uma identidade estabelecida graças às aulas, por meio da intersubjetividade de relatos que são recriados e narrados quando se sente o doce prazer do acolhimento.

Essas propostas pedagógicas da alteridade são inspiradas nas fontes das teorias do cuidado elaboradas a partir do campo feminista por Carol Gilligan (1993), problematizando as condições epistemológicas da ética política ocidental que invisibilizam-naturalizam o dano moral, a humilhação, o abuso e a subordinação dos coletivos, classes e minorias relegadas ao silêncio e à vulnerabilidade como mecanismos de submissão a trabalhos e a papeis-chave da reprodução da sociedade, como o trabalho doméstico e o cuidado das mulheres ou dos que cuidam de idosos e doentes terminais, protegem minorias religiosas e culturais da violência estatal, organizam os deslocados e os refugiados em santuários cidadãos, brindam a hospitalidade dos sem casa, entre outras ações chamadas de altruísmo radical. A atitude de despossessão de seus protagonistas é a solicitude, ou seja, uma sensibilidade solidária profunda cuja matriz é o acolhimento e a hospedagem do outro sem qualquer consideração que não uma imediata política de não-humilhação (RICARD, 2016).

Leonardo Boff (2002) ampliou os contornos da política do cuidado, estruturando uma agenda ética global de responsabilidade ecológico e de superação sistêmica das condições subalternas dos coletivos sociais, povos indígenas, comunidades campesinas, pobres, vulneráveis urbanos e minorias estigmatizadas por suas opções religiosas e linguísticas, além da orientação de gênero. Ele destaca a necessidade de desenvolver novas capacidades de 
constituição e movimentação local e global dos movimentos sociais em três chaves:

- Superação do patriarcado;

- Desmonte do poder transnacional do "capitalismo cognitivo" tecno-liberal;

- Democratização da sociedade com plena garantia de acesso e desfrute de bens naturais e culturais comuns. ${ }^{11}$

No âmbito chileno, em tendência crescente na América Latina, Carlos Calvo desenvolveu sistematicamente uma agenda de pesquisa e vínculo com projetos educacionais neo-paradigmáticos, tanto em educação comunitária quanto em instituições escolarizadas, a fim de elaborar uma teoria educacional complexa que desvele a crise do paradigma escolar, que sequestra e controla a propensão humana para a aprendizagem, disciplinando e enclausurando as relações socio-educativas no espaço e no tempo escolarizados das instituições educacionais regradas (CALVO, 2017).

Uma contribuição-chave da proposta de Calvo para a agenda de pesquisa e sistematização das práticas de educação comunitária é o convite analíticohermenêutico a cartografar os territórios educacionais (que não são apenas os escolarizados) conforma sua diversidade e segundo as manifestações neles de todas as dimensões do desenvolvimento humano a fim de suscitar "educações" emergentes e sinergias de aprendizagem entre o "estar-sendo-ocorrendo" dos estudantes e dos educadores na vida em comunidades e coletivos de pertencimento de uma etnoeducação crítica ("o caos vital do território" e os processos educacionais informais). O esforço gera processos educacionais comunitárias a partir de seus próprios núcleos éticos e culturais, matrizes simbólicas, memória histórica, relações com a natureza, línguas, confrontos, processos identitários e participação em movimentos sociais. ${ }^{12}$

\footnotetext{
${ }^{11}$ Esse enfoque do cuidado social e planetário deu lugar a um desenvolvimento importante de redes e organizações de eco-educação comunitária, bem como a uma educação comunitária feminista e não-sexista. Ver Gutiérrez e Prado (2015), Gadotti (2002) e Martínez (2016).

12 Um panorama amplo e documentado dos fundamentos, projetos, debates, controvérsias e modalidades pedagógicas, identificados neste artigo como neo-paradigmáticos e que se autodefinem a partir de diversas metáforas (holísticas, complexas, sistêmicas, caóticas e ecológicas), pode ser encontrado em Calvo e Elizalde (2010).
} 
É relevante assinalar que essas pedagogias são configuradas como uma nova onda da pedagogia crítica que foi decisiva na renovação da educação popular e da educação dos movimentos sociais na América Latina. Essas pedagogias são educações emergentes destinadas a disputar os paradigmas fabris da educação dominante a partir de um pensamento e de uma prática pedagógica altermundialistas (uma "outra educação") em seus conteúdos, formas, horizonte ético-político e cenários diversos e livres (abertos) de socialização educacional e de geração e distribuição social de aprendizagens e capacidade para o exercício da plena cidadania. Qual é o significado desse processo para a educação comunitária? Esse é o tema da próxima seção.

\section{EDUCAÇÃO POPULAR E AS PEDAGOGIAS DO COMUM: DISCUSSÃO E CONCLUSÕES}

A busca pela superação do "confinamento", da disciplina e do controle midiático e jurídico, da precarização material, da exclusão tecnológico-laboraleducacional e da negação de "direitos à diferença e às expressões vernáculas" gerou um movimento plural, global e multidimensional em suas modalidades de ação local e internacional definido como altermundialista. Esse movimento também busca a superação das condições estruturais do atual ciclo capitalista neoliberal, bem como seu impacto no mundo da vida, nas relações econômicas e no cuidado dos recursos e bens naturais do planeta.

Foi definida uma corrente social, cultural e política pró-comum como reação à pretensão dominadora do "confinamento", ou seja, da tendência a "confinar" (limitar) as demandas, capacidades e saberes dos coletivos e comunidades subordinadas às lógicas da disciplina e da "ordem da propriedade transnacional" imperante sob a colo-globalização (colonização-globalização). Conforme sustentam Laval e Dardot (2015), o comum

[...] é o nome de $m$ regime de práticas, de lutas, de instituições e de pesquisas que apontam a um futuro não-capitalista, com a busca coletivas de formas democráticas novas [...] que supõem uma reciprocidade entre os que participam de uma atividade $e$ compartilham um modo de existência que torna a prática de ação 
comum a própria condição do comum em dimensões afetivas e normativas.

A contribuição educacional desses movimentos sociais do início do presente século para uma educação "pró-comum" renova e ratifica o que a educação popular e comunitária e a pedagogia crítica latino-americana tem promovido como "teoria pedagógica": a atividade prática de aprendizagem a partir do social-cultural-contextual e a geração de saberes compartilhados para o desenvolvimento de uma "vida justa e sem exclusões" são as matrizes para "outra educação". Essas ideias foram agrupadas recentemente como pedagogias críticas do sul que articulam projetos de educação locais com estratégias de transformação institucional, curricular e pedagógica dos sistemas nacionais de educação.

Assim esses fenômenos se expressam nas escolas populares autogeridas, nos colégios públicos comunitários e nas universidades populares em alguns países de nosso continente (MEJIA, 2011; PINTO; OSORIO, 2014; CABALUZ, 2015; FAURÉ, 2016). As estratégias de educação indígena e intercultural crítica baseadas no auto-governo também atuam nessa direção a partir dos processos educacionais das comunidades, em função de seus "atributos de diversidade" e irrompendo junto às lógicas convencionais de organização educacional curricular e didática das políticas educacionais (WALSH, 2010).

A emergência de uma educação pró-comum, como movimento global, vem a redimensionar a educação comunitária ao permitir uma releitura de sua tradição, bem como a busca por sua própria atualidade e "modernidade".

Movimentos sociais e de cidadãos, plataformas de indignação, redes de solidariedade social animadas por organizações não-governamentais, redes de cooperação para o desenvolvimento local e movimentos ambientalistas, feministas e indígenas constituem o mapa dos novos modos da ação educacional em contextos comunitários. O comunitário é definido em uma projeção para o público, de modo que exige um discurso para definição do sentido políticos dos atos de dar, doar, reconhecer, se solidarizar, participar, 
resistir e acolher em consonância com os valores de uma democracia inclusiva e participativa. ${ }^{13}$

A "pedagogia do comum" torna-se cidadã (convoca os cidadãos a participarem na sociedade) e isso implica modos de praticar o associativismo sob dinâmicos institucionais distintas das tradicionais (limitadas a dinâmicas representativas, por exemplo), fortalecendo as questões participativas e vias diretas que colocam o individualismo sob um prisma crítico. Assim, não é a participação em comunidade uma demanda pelo público, mas uma demanda por um catálogo de novos direitos que resguardem o uso e a sustentabilidade dos bens naturais e culturais comuns.

Nese contextos surgem manifestações de solidariedade, mobilização cidadã, reciprocidade e cuidado que estabelecem redes de atuação e um pensamento crítico acerca das noções de desenvolvimento e bem-estar ecohumano (RAMIS, 2017). Esse fenômeno atualmente se expande, já que a partir do civismo pro-comum surgem iniciativas e modelos de atuação social que dinamizam e liberam a democracias de suas ataduras formais, tornando-a mais direta, participativa e confiável para a cidadania. Estamos diante de uma possibilidade de sustentar novamente a democracia a partir de baixo, a partir da ação dos indivíduos e de suas redes de afirmação identitárias e de memória.

No entanto, o novo civismo, tal como o conhecemos junto aos movimentos sociais latino-americanos e globais (TORRES, 2015), não constitui um modo de protecionismo isolado e meramente reativo em face do medo e do risco, mas um modo de praticar reflexivamente o "dar", o "participar" e o "atuar com os outros". Trata-se de uma maneira (nova?) de politizar (compartilhar e tornar público) as emoções, os afetos, as resistências culturais, a demanda por reconhecimento da diferença, as identidades vernáculas e a produção de imaginários sociais que possam superar a ordem econômica global dominante por meio de comunidades de ação e crítica presentes em formas orgânicas diversas. Nesse sentido, destacamos as redes e os movimentos sociais, as plataformas de participação

${ }^{13} \mathrm{Em}$ estudo sobre as pedagogias dos movimentos sociais latino-americanos mais recentes, Alfonso Torres (2015) desenvolve o conceito de "horizonte histórico-ético" dos processos formativos que ocorrem na geração e no desenvolvimento de tais movimentos, bem como enfatizando as metodologias de trabalho educacional praticadas, tais como o diálogo de saberes, o diálogo cultural, a pesquisa-ação participativa e a sistematização de experiências e projetos. 
cidadã, as frentes amplas, os movimentos indígenas, os grupos feministas, as pautas ecológicas, as coalizões multisetoriais e os "grupos de tarefa" para a denúncia das políticas globais de "confinamento neoliberal", tendo em vista os cenários da educação comunitária emergente.

Evidentemente devemos entender essa solidariedade-reciprocidadecuidado como um "produto" cultural, uma expressão de uma sensibilidade moral alternativa à dominante em nossa época. As resistências ao "confinamento" estão gerando também o rechaço de preceitos morais estabelecidos, pois os sujeitos dessas novas cidadanias comunitárias se sentem capazes de construir suas próprias éticas do público (OSORIO, 2016). Não estamos em uma época vazia de alternativas morais, mas em uma época em que se manifestam coletivos que configuram éticas. Estas são processadas por meio do escrutínio da consciência individual, não por meio de qualquer autoridade e instituição que antes poderiam ter o controle hegemônico da orientação moral.

Bauman (2017) identifica essas comunidades que resistem à violação e ao confinamento, vítimas dos danos colaterais da globalização e sob o risco de serem declaradas descartáveis ou inviáveis conforme a ordem global, como comunidades plurais, abertas e não-panópticas. Elas são radicalmente posicionadas em uma luta contra a não-humilhação e a não-discriminação como atributos fundantes de toda estratégia contemporânea de transformação social.

O aspecto mais interessante do fenômeno descrito é que esse processo de emergência social, que se manifesta nas iniciativas e programas educacionais que chamamos "pró-comum", incorpora novas perguntas acerca da prática do comunitário em um contexto crescentemente reacionário e hostil, com crescentes doses de xenofobia e aporofobia (CHUL HAN, 2017; CORTINA, 2017) ao estrangeiro, aos diversos, aos imigrantes, aos refugiados e às pessoas deslocadas por questões políticas, climáticas, guerras civis e religiosas ou crise alimentar.

Essas questões fazem referência às capacidades do capital cívico, comunicacional e de diálogo intercultural das sociedades, bem como às condições políticas para adoção de acordos que condenem todo tipo de discriminação. Em uma perspectiva mais ampla, surge a pergunta a respeito das 
possibilidades de construção de sentidos comuns na sociedade através de processos constituintes gerados junto à base social em uma lógica de deliberação cidadão não-violenta, pois capaz de inverter os marcos políticos desgastados pelas convenções da democracia representativa. Isso adquiriu expressão no movimento estudantil chileno de 2011 e nas mobilizações do M15 espanhol, em uma dinâmica de superação da democracia por meio de sua própria ampliação e radicalização (ROSANVALLON, 2017).

O desenvolvimento de ambas as perspectivas tem consequências relevantes: a primeira acentua a aprendizagem do acolhimento e da participação junto à diversidade como valores reconhecidos socialmente e validados em meios institucionais. A segunda promove o associativismo e as redes de atuação pública, bem como fomenta a formação da cidadania, destacando um tipo de contrato político de alcance institucional, tendo em vista uma ética civil vinculante.

Ambas as direções evidenciam os atributos e as potencialidades de uma nova educação comunitária não apenas como realidade sociológica, mas como desdobramentos sobre a sociedade. A educação comunitária é abordada junto a outros processos de distribuição social do poder, em um conjunto de atributos, capacidades e recursos cidadãos, éticos, comunicacionais, de reciprocidadecuidado, pedagógicos e organizacionais, a fim de sustentar uma nova matriz da vida democrática fundamentada no reconhecimento da diversidade, na inclusão, na participação e no desenvolvimento humano pró-comum.

Tradução: Felipe Ziotti Narita

Artigo publicado originalmente em espanhol na revista acadêmica chilena Trenzar em 2018. A presente tradução foi autorizada pelo autor, a quem agradecemos o pronto interesse e a participação em nossa coletânea.

\section{REFERÊNCIAS}

ALARCÓN, P. Coexistencia y educación. Santiago: Cuarto Propio, 2015.

ASSMANN, H. Placer y ternura en la educación. México DF: AlfaomegaNarcea, 2013. 
BARBIER, R. La invesigación-acción-existencial, integral, personal y comunitaria. Visión Docente con Ciencia, v. 44, 2008.

BAUMAN, Z. El arte de la vida. México DF: Paidós, 2017.

BOLIVAR, A. De nobis ipsis silemus? Epistemología de la investigación biografico-narrativa en educación. Revista de Investigación Educativa, v. 4, n. 1, 2002.

BOFF, L. El cuidado esencial. Madri: Trotta, 2002.

BRUNNER, J. J. La fabrica de historias. México DF: FCE, 2003.

CABALUZ, F. Entramando pedagogías críticas latinoamericanas. Santiago: Quimantú, 2015.

CALVO, C. Del mapa escolar a territorio educativo. La Serena: Universidad de La Serena, 2013.

CALVO, C. Ingenuos, ignorantes, inocentes: de la educación informal a la escuela autoorganizada. La Serena: Universidad de La Serena, 2017.

CARBONELL, J. Pedagogías del siglo XXI. Barcelona: Octaedro, 2015.

CASTELLS, M. Redes de indignación y esperanza. Madri: Allianza, 2012.

COLECTIVO DIATRIBA. Educación publica-comunitaria: propuesta conrahegemónica para la transformación social. Revista de Pedagogia Crítica, Santiago, v. 11, 2012.

CHUL-HAN, B. La expulsión de lo distinto. Barcelona: Herder, 2017.

CORTINA, A. Aporofobia: el rechazo al pobre. Barcelona: Paidós, 2017.

CUSSIÁNOVICH, A. Aprender la condición humana. Lima: IFEJANT, 2010.

DAUSIEN, B. Aprendizaje biografico y biograficidad. Sinéctica, v. 45, n. 2, 2015.

ELIZALDE, A.; CALVO, C. (Eds.). Educación y complejidad. Santiago: Polis, 2010.

FAURÉ, D.; MIRANDA, E. (Eds.). 4 de agosto: testimonios de una revuelta popular. Santiago: Universidad de Chile, 2016.

FAURÉ, D. Auge y caída de la educación popular en Chile. 171 f. Dissertação (Mestrado em Educação) - Universidade do Chile, 2011. 
FAURÉ, D. Las prácticas de (auto) educación popular en Chile postdictadura y la propuesta del control comunitario. Revista de Educación de Adultos y Procesos Formativos, Valparaíso, v. 3, 2016.

FERRADA, D.; FLECHA, R. El modelo dialógico de la pedagogía. Estudios Pedagógicos, v. 34, 2008.

GADOTTI, M. Pedagogia de la tierra. México DF: Siglo XXI, 2002.

GILLIGAN, C. In a different voice. Cambridge: Harvard University Press, 1993.

GHISO, A. Potenciando la diversidad. 2000.

GONZÁLEZ, P.; RAMOS, R. La otra educación. Monografia (Trabalho de Conclusão de Curso em Educação) - Universidade do Chile, Santiago, 2013.

GUTIÉRREZ, P. PRADO, C. Ecopedagogía y ciudadanía planetaria. México DF: De La Salle, 2015.

GRAMSCI, A. Los intelectuales y la organización de la cultura. Buenos Aires: Nueva Visión, 2004.

HALL, B.; COLVER, D.; CROWTHER, J.; SCANDRETT, E. Learning and education for a better world. Nova York: Sense Publishers, 2012.

ILLICH, Ivan. El trabajo fantasma. Santiago: Papel Calco, 2016.

LAVAL, C.; DARDOT, P. Común. Barcelona: Gedisa, 2015.

MARTÍNEZ, I. Construcción de una pedagogía feminista para una ciudadanía transformadora y contra-hegemonica. Foro de Educación, v. 14, n. 20, 2016.

MEJÍA, M. R. Educaciones y pedagogias críticas desde el sur. La Paz: Ministerio de Educación, 2011.

MÉLICH, J. El texto como otro. Art Brevis, Santiago, v. 2, 1996.

MONTAGUE, X. Analítica o evocadora: el debate olvidado de la etnografía. FQS, v. 17, n. 3, 2016.

OSORIO, J. Profundizando el aporta de la educación popular y el CEAAL en America Latina y el Caribe. La Piragua, v. 20, 2003.

OSORIO, J. Pedagogía y ética en la construcción de ciudadanía. Polis, v. 7, 2004. 
OSORIO, J. Educação popular: a atualiação do desafio de construir o bem comum na sociedade. In: PONTUAL, P.; TIMOTHY, I. (Eds.). Educação popular na América Latina. Brasília: Unesco, 2006.

OSORIO, J. El corazón de la educación: reflexiones sobre nuevos paradigmas educativos e inteligencias pedagógicas arquetípicas. In: OSORIO, J.; WEINSTEIN, L. (Eds.). El asombro de la educación. Santiago: Universidad Bolivariana, 2013.

OSORIO, J. Memorias y desafios de la educación popular en Chile. Decisio, v. 40, 2015.

OSORIO, J. Ciudadanía en movimiento: na agenda para una educación ciudadana crítica. Revista Internacional sobre Investigación en Educación Global y para el Desarrollo, v. 9, 2016.

ORTIZ, I.; BURKE, S.; BERRADA, M.; CORTES, H. World protests, 2006-2013. Nova York: Friedrich Ebert Foundation, 2013.

PADIERNA, M. Educación y movimientos sociales. Pampedia, v. 6, 2009.

PAREDES, J. Movilizarse tiene sentido. Psicoperspectivas, v. 13, 2013.

RICARD, M. En defensa del altruismo. Barcenola: Urano, 2016.

PINTO, R.; OSORIO, J. Pedagogía crítica para una educación pública transformadora en América Latina. Lima: Dettama Magisterial, 2014.

RAMIS, A. Buenes comunes y democracia. Santiago: LOM, 2017.

ROSANVALLON, P. La contrademocracia. Buenos Aires: Manantial, 2007.

SCHÖNGUT, G.; PUJOL, J. Relatos metodológicos: difractando experiencias narrativas de investigación. FQS, v. 16, 2015.

TORRES, A. Educación popular y movimientos sociales en América Latina. Buenos Aires: Biblos, 2015.

TORRES, A. La educación popular. Bogotá: El Búho, 2016.

VALLEJO, S. La pedagogía de la alteridad: un modo de habitar y comprender la experiencia educativa del presente. Revista Fundación Universitaria Luis Amigó, v. 2, 2014. 
WALSH, C. Interculturalidad critica y educación intercultural. In: VIAÑA, J. (Ed.). Construyendo interculturalidad crítica. La Paz: Instituto Internacional de Convenio Andrés Bello, 2010.

ZIBECHI, R. Autnomías y emancipaciones. México DF: Bajo Tierra, 2008.

Recebido em: 30/04/2020

Aprovado em: 02/09/2020 